\title{
Patterns of food and nutrient intakes in Italy and their application to the development of food-based dietary guidelines
}

\author{
Aida Turrini*, Catherine Leclercq and Amleto D'Amicis \\ Istituto Nazionale della Nutrizione, Via Ardeatina, 546, I-00178 Rome, Italy
}

\begin{abstract}
Patterns of food and nutrient intakes in Italy were estimated starting from a nationwide food survey carried out by the National Institute of Nutrition (NIN) in 1994-6, called INN-CA 1995. The present analysis looks at food and nutrient intakes of the subsample of the adults (18-60year-old individuals). In particular, the two extreme quartiles of the distribution of total fat intake expressed as percentage of energy were considered in the analysis. The results showed that the subjects included in the fourth quartile (high-fat consumers) consumed fewer vegetables than the subjects in the first quartile (low-fat consumers). Furthermore, high-fat consumers had a tendency to have an unbalanced diet, whereas the low-fat consumers present a better pattern. In synthesis, $50 \%$ of the adults reach the goal of at least $400 \mathrm{~g}$ of vegetables and fruit daily, and $25 \%$ consume less than $30 \%$ of energy from total fats. Convincing that part of the population whose diet does not comply with dietary goals to come back to the Mediterranean tradition might be a priority for nutrition education in Italy.
\end{abstract}

Italian patterns: Food intakes: Nutrient intakes

The ultimate aim of nutrition policy is to reduce the prevalence of nutrition-related diseases and the social costs and human suffering deriving from them. Nutrition policy is developed according to specific national circumstances in terms of food supply, food culture, economic conditions and patterns of disease. In many ways, the Italian context is similar to that of other western affluent societies, with problems of overconsumption and wrong dietary choices rather than of insufficient availability of food. However, Italy presents some specific characteristics that have influenced the elements of nutrition policies developed in the past and that will be crucial for the future of nutrition policy in this country.

The geographic position of Mediterranean countries has bestowed them special characteristics as regards climate and soil leading to an agriculture unique for the variety of its products (Pilo, 1991). Moreover, thanks to its history of land and maritime commercial activity and to the large place occupied in the culture by delight in good food, a very rich culinary tradition has developed. As the result of these and other factors, the Mediterranean diet is considered a most varied and complete way of eating (Keys, 1995).

The diet consumed in the rural population of South Italy in the early 1960s was based primarily on cereals, fresh vegetables and olive oil. It was low in fat, in animal protein and in cholesterol, and high in fibre (Ferro-Luzzi \& Sette,
1989). The largest quantitative and qualitative change in the Italian diet occurred after the Second World War (FerroLuzzi \& Sette, 1989), with a gradual shift towards a higher nutrient density and a progressively altered structure of the diet (Ferro-Luzzio \& Sette, 1989; Cialfa et al. 1991). The extent of these changes has been more marked in the South, with the WHO national guidelines, population goals for disease prevention of 'no more than $30 \%$ energy from fat', (WHO, 1990) being gradually approached and then even exceeded: fat intake increased from $28 \%$ energy in the 1960 s to $36 \%$ in the 1980 s (ICN, 1992). This intake appeared to be stabilized over $30 \%$ energy in the survey conducted in the 1990s (Conforti et al. 1996). The north/ south differences have been greatly attenuated in the last 30 years. However, a clear-cut north/south trend persists within Italy for olive oil intake ( $80 \%$ of total fats and oils in the south versus $20 \%$ in the north) and for tomatoes and other fruits and vegetables (almost three times as much in the south than the north).

Among countries situated around the Mediterranean basin, the current Italian diet is, with the Greek and the Spanish, that with more 'Mediterranean characteristics'. According to Food Balance Sheets, in 1988-90 the estimated percentage of energy derived from olive oil was $9 \%$ in Italy, far higher than that reported in Portugal $(3 \%)$ and in France and Yugoslavia (less than 1\%) (FAO, 1992). Estimated

\footnotetext{
Abbreviations: WHO, World Health Organization; FAO, Food and Agricultural Organization; NIN, National Institute of Nutrition; ISTAT, National Institute of Statistics; BMR, basic metabolism/energy ratio.

* Corresponding author: Dr A. Turrini, fax +396503 1592, email turrini@inn.ingrm.it
} 
Table 1. The seven messages of the Italian Dietary Guidelines for Healthy Eating disseminated by the Italian Ministry of Agriculture in 1986-1988 and 1997-1998

\begin{tabular}{ll}
\hline 1986-1988 campaign & \multicolumn{1}{c}{ 1997-1998 campaign } \\
\hline 1. Mind your body weight & 1. Control your body weight and keep active \\
2. More vegetable starch and more fibre & 2. More cereals, pulses, fruit and vegetables \\
3. Salt? little is better & 3. Salt? better not use too much \\
4. Why and how to vary your diet & 4. Why and how to vary your diet \\
5. Alcohol: if you drink, do so in moderation & 5. Alcohol: if you drink, do so in moderation \\
6. Sweet products: which, how often and how much & 6. Sugars and sweet products: which, how often and how much \\
7. Less fat and cholesterol & 7. How much fat, which fats \\
\hline
\end{tabular}

Source: NIN $(1986,1997)$.

intake of fruit was $380 \mathrm{~g} / \mathrm{d}$ in Italy, higher than in Portugal, France and Yugoslavia (mean $200 \mathrm{~g} / \mathrm{d}$ ). Intake of vegetables was $470 \mathrm{~g} / \mathrm{d}$ in Italy versus $330 \mathrm{~g} / \mathrm{d}$ in France and $210 \mathrm{~g} / \mathrm{d}$ in Yugoslavia.

In the last 20 years, several national campaigns have been performed by the Ministry of Agriculture in collaboration with the National Institute of Nutrition (NIN). Both their information content and the strategy of their transfer to the population have evolved over time in an attempt to respond to the true information need of the Italian population and to become increasingly more effective.

The first national campaign was conducted in 1975. In those years, problems of undernutrition still persisted, especially in the backward areas of southern Italy. The main objective of the campaign was thus to promote the consumption of a sufficient and nutritious diet. Therefore, the issues addressed by this campaign were the nutrient content of foods, how to avoid losses of nutrients during the cooking process, which foods are to be present in the diet, etc.

A second campaign was conducted in 1981. The aim in this case was the promotion of the nutritional and health benefits of the Mediterranean diet for the prevention of chronic degenerative diseases. The population was advised to combine seven food groups in their diet: 1 , meat, fish and egg products; 2, milk and milk products; 3 , cereals and tubers; 4, legumes; 5, fats; 6, fruit and vegetable main sources of carotenoids; 7 , fruit and vegetable main sources of vitamin $\mathrm{C}$.

The third campaign was conducted between 1986 and 1988, based on the first Dietary Guidelines for a Healthy Nutrition, which were elaborated in an ad hoc expert Advisory Commission coordinated by the National Institute of Nutrition (NIN, 1986). The prevention of chronic degenerative diseases was the main objective. The recommendations were of a non-quantitative nature and emphasize the importance of an overall healthy eating pattern (which largely reflects the traditional Italian dietary pattern) rather than promoting the consumption of specific food items. Four million copies of the guidelines were dispatched throughout Italy (Ticca, 1991). The messages of these guidelines have been updated in the second edition of the Dietary Guidelines, when a new campaign was launched by the NIN (1997). Where possible, the emphasis was shifted from nutrients to foods, i.e. mentioning cereals, pulses, fruit and vegetables instead of vegetable starch and fibre (see Table 1). This has been Italy's first step towards food-based dietary guidelines. The main messages related to fat, fibre, fruit and vegetables are qualitative. However, some quantitative dietary goals have been established by an expert Italian working group in two occasions: 1, when the Italian Country Paper was prepared in occasion of the International Conference on Nutrition (ICN, 1992); and 2, within the frame of the definition of Italian Recommended Dietary Allowances (RDAs), known as 'LARN' in Italy (SINU, 1996). These goals are presented in Table 2, and are similar to that of other western countries, in line with those established by a WHO study group (1990).

\section{Methods \\ Survey methodology}

The present work is based on data collected in the latest survey conducted by the NIN in the period 1994-1996, named INN-CA 1995 (central year). This nationwide survey was aimed at outlining food consumption patterns of the Italian population about ten years after the previous one (Saba et al. 1990). The study was conducted on a multicentre base and involved 15 different Collaborating Centres. The response rate was rather low (about $25 \%$ ) because of the burden for participants. This was anticipated, and addressed by selecting a certain number of substitutes in advance for non-respondent households. The sample consisted of 1200 households (about 3600 subjects), which was geographically representative for Italy. The survey covered four seasons and used a $7 \mathrm{~d}$ weighed record.

Table 2. Italian quantitative dietary goals related to total fat, total dietary fibres, and fruit and vegetables

\begin{tabular}{lccc}
\hline Source & Total fat & Total dietary fibre & Fruit and vegetables \\
\hline Population nutrient goal (ICN, 1992) & $<30 \%$ & $>27 \mathrm{~g}$ & - \\
Italian RDAs (SINU, 1996) & $25 \%$ & $30 \mathrm{~g}$ & - \\
Italian Dietary Guidelines (NIN, 1997) & $<30 \%(25-30 \%)$ & $30 \mathrm{~g}$ & $>400 \mathrm{~g}$ \\
\hline
\end{tabular}

$\mathrm{RDA}=$ Recommended Dietary Allowances. 
Food data forms and questionnaires were administered to subjects at two different levels in order to reflect all aspects of food consumption patterns. Therefore, quantitative estimates were completed by means of several qualitative features. In particular, a food inventory, a purchase/waste diary and a recipes form (weighed ingredients and cooking method) were filled in at household level, whereas the individuals recorded a consumption diary. One household questionnaire about food-related activities to that person responsible within each household, and a second questionnaire for each household member provided ancillary information, to be utilized in modelling food consumption patterns.

Of the nutrients studied, with the exception of carbohydrates and fibre, the proportion of foods for which data were missing was less than $1 \%$. However, data on carbohydrates were missing for $2.5 \%$ of foods and on fibre for $14.7 \%$ of foods.

Furthermore, for some important sources of fibre (bread, pasta, pulses) a third of food items did not have a value for dietary fibre content in the databases. As a consequence, the estimated dietary fibre intakes were not considered reliable and are not presented.

\section{Preliminary data processing}

Completeness and consistency of the surveyed data had been checked by applying the following statements:

i) Food quantities had to be expressed as single food items, raw and edible part only. Therefore, mixed dishes were split into single components according to the collected recipes 'if prepared at home' or standard recipes 'if consumed out':

ii) Each food item was coded by utilizing an ad hoc system. The latter will allow single food items to be identified and aggregated into food groups:

iii) Specific software procedures have been implemented:

a) to enter data in computerized systems;

b) to perform a consistency check of quantitative data.

\section{Nutrients and energy assessment}

Each food item was assigned a set of composition data (i.e. that of an identical or similar food), taken from the latest version of the Italian Food Composition Table (Carnovale \& Marletta, 1997), which represents the official source of such information in Italy.

The biggest problem encountered concerned the discrepancy between the number of surveyed food items (about 42000 food items) and the number of foods for which there was available data (614 items). Not all surveyed items were really different from each other, but, nevertheless, some problems were encountered in assigning the right composition data to all foods. To help in the interpretation of the results, the number of foods for which data on specific nutrients were missing was assessed.

\section{Results}

Mean daily intake of energy and the contributing macronutrients (\%energy) are presented in Table 3. From this table it appears that fat intake is only slightly over the dietary goal of $30 \%$ energy, and that the dietary goal for fruit and vegetables intake is reached (over $400 \mathrm{~g}$ ). Furthermore, the sample was divided in quartiles according to their intake of fat as a proportion of energy intake, to their absolute intake of fat and to their overall intake of fruit and vegetables, and the first (low fat intake) and the fourth quartiles (high fat intake) were compared in the analysis.

It can be observed that the difference in mean and median values of macronutrient intake, expressed as a percentage of energy, is greater when comparing low and high consumers of fat than the difference between males and females. Therefore, the former was used to compare the upper limit of the low consumers and the lower limit of the high consumers. Data are presented in Table 4, together with mean and median intakes within these two groups.

When the data were expressed in this way, the difference between high and low consumers was small for percent

Table 3. Mean intakes of nutrients and energy in the total sample (18-60 years old) according to gender and quartiles of total fat intake (\%energy)

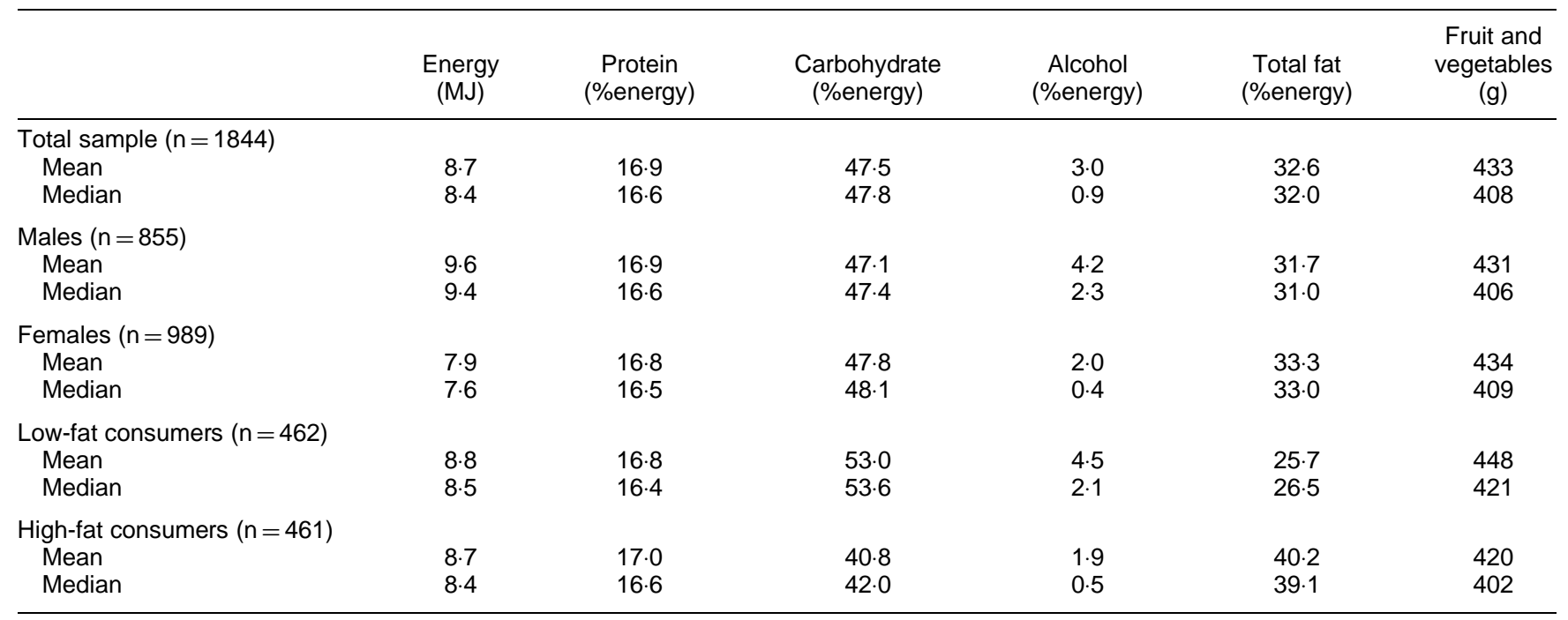


Table 4. Limits, mean and median of quartiles of total fat intake ( $g$ and \%energy), and fruit and vegetables intake (g)

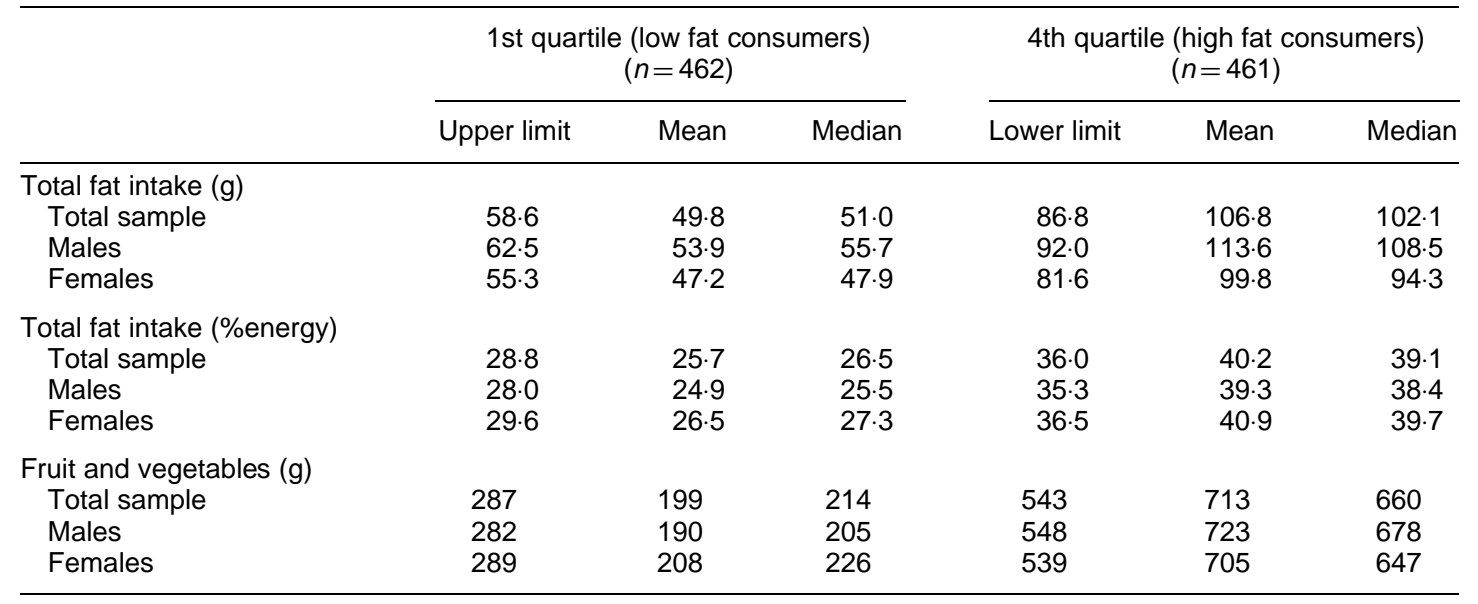

intake of fat: $36 \%$ (lower limit, high consumers) compared with $29 \%$ (upper limit, low consumers) (7 percentage points lower), indicating that the distribution is narrow and that a small proportion of the population derive a high proportion of energy from fat. In terms of fruit and vegetables, the difference between the low and high consumers was greater: less than $287 \mathrm{~g}$ in the lowest consumers compared with above $543 \mathrm{~g}$ in the highest consumers (twice as high). More than a quarter of the sample have an insufficient intake of fruit and vegetables. The goal of $400 \mathrm{~g} / \mathrm{d}$ of fruit and vegetables is reached by more than $50 \%$ of the total sample $($ median $=408 \mathrm{~g}$ ) and exceeded by $25 \%$ of the sample (lower limit, high consumers $=543 \mathrm{~g}$ ).

Intake of energy and percent energy from protein was similar for low and high consumers of fat. For other macronutrients, the results show an opposite trend to total fat intake. In those with a lower fat intake, fats were substituted with a little more alcohol and far more carbohydrates. The higher intake of carbohydrates was mainly due to complex carbohydrate $(211 \mathrm{~g} / \mathrm{d}$ for the low-intake group vs. $157 \mathrm{~g} / \mathrm{d}$ for the high-intake group) and only a minor contribution was made by simple sugar $(86 \mathrm{~g} / \mathrm{d}$ for the

Table 5a. Mean and median food intakes $(\mathrm{g} / \mathrm{d})$ and $\%$ consumers of foods among Italian adults with low $(<28.8 \%)$ and high $(>36.0 \%)$ energy intake from fat

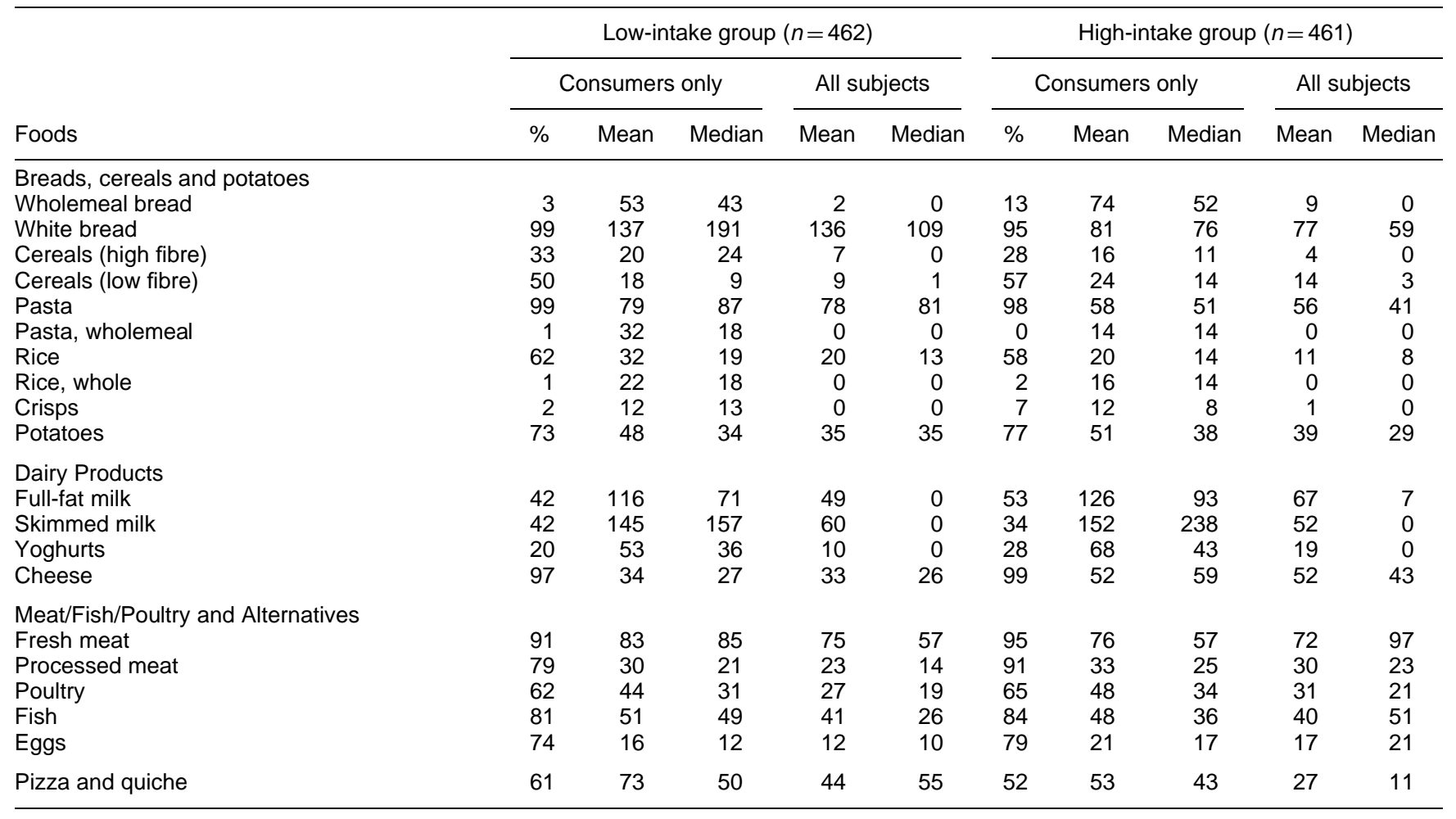


low-intake group vs. $71 \mathrm{~g} / \mathrm{d}$ for the high-intake group). The higher intake of alcohol was evident when the data were expressed as percent energy and also when expressed in $\mathrm{g}$ of alcohol per day $(16.2 \mathrm{~g}$ for the low-intake group vs. $7 \mathrm{~g}$ for the high-intake group).

In order to get a better insight into the food consumption patterns of the low- and high-intake groups of total fat (\%energy), the daily average intakes per 54 food categories were assessed (Table 5a, b).

In terms of foods, subjects included among the low-intake group for fat ate on average $75 \mathrm{~g}$ more of cereals and potatoes than those included in the high-intake group. They consumed daily $17 \mathrm{~g}$ more pizza and quiche, $90 \mathrm{~g}$ more alcoholic beverages, and $28 \mathrm{~g}$ more fruit and vegetables. On the other hand, they consumed daily $38 \mathrm{~g}$ less of dairy products, $20 \mathrm{~g}$ less fat and spreads, $15 \mathrm{~g}$ less of desserts/cakes/buns. Only minor differences were found between the lowest and highest consumers in terms of intake of confectionery $(2 \mathrm{~g})$, soups and sauces $(1 \mathrm{~g})$, meat/ fish/poultry (6g) and other foods.

The main food groups responsible for higher fat intake among the highest consumers are therefore probably: 1, fat and spreads; 2 , dairy products; 3 , dessert/cakes/buns. A further analysis shows that, among the sources of fat, consumption of butter, seed oils and olive oil were higher in the high-intake group. As for dairy products, the difference

Table 5b. Mean and median food intakes $(\mathrm{g} / \mathrm{d})$ and \% consumers of foods among Italian adults with low $(<28.8 \%)$ and high ( $>36.0 \%)$ energy intake from fat

\begin{tabular}{|c|c|c|c|c|c|c|c|c|c|c|}
\hline \multirow[b]{2}{*}{ Foods } & \multicolumn{5}{|c|}{ Low-intake group $(n=462)$} & \multicolumn{5}{|c|}{ High-intake group $(n=461)$} \\
\hline & $\%$ & Mean & Median & Mean & Median & $\%$ & Mean & Median & Mean & Median \\
\hline $\begin{array}{l}\text { Fruit and vegetables } \\
\text { Total fruit and vegetables } \\
\text { Citrus fruit } \\
\text { Other fruit } \\
\text { Processed fruit } \\
\text { Fruit juices } \\
\text { Pulses } \\
\text { Other vegetables }\end{array}$ & $\begin{array}{r}100 \\
62 \\
89 \\
6 \\
25 \\
54 \\
100\end{array}$ & $\begin{array}{r}448 \\
70 \\
182 \\
35 \\
72 \\
26 \\
207\end{array}$ & $\begin{array}{r}421 \\
36 \\
125 \\
16 \\
52 \\
17 \\
194\end{array}$ & $\begin{array}{r}448 \\
44 \\
162 \\
2 \\
18 \\
14 \\
207\end{array}$ & $\begin{array}{r}421 \\
2 \\
109 \\
0 \\
0 \\
6 \\
194\end{array}$ & $\begin{array}{r}100 \\
59 \\
90 \\
11 \\
28 \\
51 \\
100\end{array}$ & $\begin{array}{r}420 \\
51 \\
150 \\
10 \\
57 \\
20 \\
228\end{array}$ & $\begin{array}{r}402 \\
21 \\
109 \\
6 \\
29 \\
14 \\
197\end{array}$ & $\begin{array}{r}420 \\
30 \\
135 \\
1 \\
16 \\
10 \\
228\end{array}$ & $\begin{array}{r}402 \\
2 \\
94 \\
0 \\
0 \\
0 \\
197\end{array}$ \\
\hline $\begin{array}{l}\text { Fats and spreads } \\
\text { Butter and other animal fats } \\
\text { Margarine } \\
\text { Olive oil } \\
\text { Seeds oil }\end{array}$ & $\begin{array}{r}47 \\
3 \\
95 \\
26\end{array}$ & $\begin{array}{r}5 \\
4 \\
15 \\
6\end{array}$ & $\begin{array}{r}3 \\
2 \\
16 \\
3\end{array}$ & $\begin{array}{r}2 \\
0 \\
14 \\
2\end{array}$ & $\begin{array}{r}0 \\
0 \\
15 \\
0\end{array}$ & $\begin{array}{l}66 \\
10 \\
95 \\
37\end{array}$ & $\begin{array}{r}11 \\
6 \\
26 \\
17\end{array}$ & $\begin{array}{r}6 \\
3 \\
20 \\
9\end{array}$ & $\begin{array}{r}7 \\
1 \\
25 \\
6\end{array}$ & $\begin{array}{r}3 \\
0 \\
20 \\
0\end{array}$ \\
\hline $\begin{array}{l}\text { Confectionery, etc. } \\
\text { Sugar and honey } \\
\text { Preserves } \\
\text { Chocolate and other cocoa products } \\
\text { Other sweets } \\
\text { Nuts }\end{array}$ & $\begin{array}{r}84 \\
4 \\
11 \\
17 \\
6\end{array}$ & $\begin{array}{r}17 \\
3 \\
6 \\
14 \\
19\end{array}$ & $\begin{array}{r}11 \\
2 \\
4 \\
15 \\
13\end{array}$ & $\begin{array}{r}14 \\
0 \\
1 \\
2 \\
1\end{array}$ & $\begin{array}{l}9 \\
0 \\
0 \\
0 \\
0\end{array}$ & $\begin{array}{r}82 \\
7 \\
21 \\
18 \\
18\end{array}$ & $\begin{array}{r}13 \\
2 \\
9 \\
8 \\
13\end{array}$ & $\begin{array}{r}13 \\
2 \\
8 \\
6 \\
7\end{array}$ & $\begin{array}{r}11 \\
0 \\
2 \\
1 \\
2\end{array}$ & $\begin{array}{l}8 \\
0 \\
0 \\
0 \\
0\end{array}$ \\
\hline $\begin{array}{l}\text { Drinks } \\
\text { Tea } \\
\text { Coffee } \\
\text { Camomile, herb tea } \\
\text { Drinking chocolate } \\
\text { Soft drinks }\end{array}$ & $\begin{array}{r}27 \\
87 \\
8 \\
0 \\
29\end{array}$ & $\begin{array}{r}1 \\
10 \\
1 \\
2 \\
109\end{array}$ & $\begin{array}{r}2 \\
7 \\
1 \\
2 \\
83\end{array}$ & $\begin{array}{r}0 \\
9 \\
0 \\
0 \\
32\end{array}$ & $\begin{array}{l}0 \\
8 \\
0 \\
0 \\
0\end{array}$ & $\begin{array}{r}30 \\
86 \\
7 \\
1 \\
26\end{array}$ & $\begin{array}{r}1 \\
10 \\
1 \\
1 \\
96\end{array}$ & $\begin{array}{r}1 \\
8 \\
1 \\
1 \\
47\end{array}$ & $\begin{array}{r}0 \\
9 \\
0 \\
0 \\
25\end{array}$ & $\begin{array}{l}0 \\
7 \\
0 \\
0 \\
0\end{array}$ \\
\hline $\begin{array}{l}\text { Other foods } \\
\text { Water } \\
\text { Alcoholic beverages } \\
\text { Miscellaneous } \\
\text { Pre-prepared dishes }\end{array}$ & $\begin{array}{r}100 \\
71 \\
98 \\
12\end{array}$ & $\begin{array}{r}670 \\
225 \\
13 \\
29\end{array}$ & $\begin{array}{r}486 \\
255 \\
6 \\
25\end{array}$ & $\begin{array}{r}668 \\
160 \\
13 \\
4\end{array}$ & $\begin{array}{r}486 \\
95 \\
8 \\
0\end{array}$ & $\begin{array}{r}100 \\
63 \\
99 \\
24\end{array}$ & $\begin{array}{r}703 \\
113 \\
13 \\
32\end{array}$ & $\begin{array}{r}568 \\
79 \\
8 \\
30\end{array}$ & $\begin{array}{r}703 \\
72 \\
13 \\
8\end{array}$ & $\begin{array}{r}568 \\
25 \\
8 \\
0\end{array}$ \\
\hline
\end{tabular}


was due to a higher intake of whole milk, yoghurt and cheese, whereas the intake of skimmed milk was higher in the low-intake group. The number of consumers of cheese was similar in both groups (nearly $100 \%$ ) but their intake was higher among the highest consumers of fat. For desserts/ cakes and buns, most of the difference was due to higher intakes of ice-cream, croissants and pastries, whereas the intake of biscuits was similar in both quartiles.

\section{Discussion}

The response rate was low but an analysis of the sample revealed no gross bias. The level of education observed was only slightly higher than that of the general Italian population as assessed in the Italian census (ISTAT, 1995). Most households included more than one subject: therefore, the intraindividual variability might be slightly underestimated but this should not have any effect on mean value assessed. The survey design included recording of the quantities of foods eaten, both at household and individual level, in order to analyse the role of the 'structure of the family' as a factor influencing individual consumption, since adults in particular make their own food choices when eating outside of the house. A very common flaw of dietary analysis studies is the underestimation of food and beverages intakes. The basic metabolism/energy (BMR) ratio may be used as a check of reliability of results, indicating that no gross under-reporting occurred.

The BMR ratio found in females was extremely close to the Physical Activity Level indicated in Italian RDAs for sedentary females (1.42), suggesting that the level of underreporting was probably very low. Since it was intended to identify subjects that met a dietary goal expressed as "eat less than', there was a high risk of selecting a sample of under-reporting subjects. Under-reporting is a problem especially if it is selective for specific foods. Even if intakes are expressed in terms of percent of energy, subjects eating less than $30 \%$ of energy from fats could have been subjects that under-reported their fat intake. Mean BMR ratio was therefore assessed in each quartile of fat intake. Even the lowest ratio (males in the high-intake of fat group) was above the cut-off point $(1 \cdot 27)$.

The results suggest that the diet of those in the highest quartile for fat (\%energy) was unbalanced, whereas it was balanced in the $25 \%$ of the sample with the lowest intakes (first quartile). People eating less fat ate slightly more free sugars but this might be partly associated with the sugars present in fruit. They have a slightly higher intake of alcohol which is not due to an accident of mathematics (low percent of energy from fat leading to a higher percentage of all other nutrients) because it is true also in absolute terms. However, since alcohol intake was probably under-reported by many subjects it might be that subjects consuming less fat were more health-oriented and that they were more reliable in reporting their intake of alcoholic drinks. In the highest group for fat intake, the intakes of most sources of fats were increased. For daily foods, the percentage of consumers was similar but their intake was higher. Both the goals of 'less than $30 \%$ of energy from fats' and that of 'more than $400 \mathrm{~g}$ of fruit and vegetables' are attainable. The former is already met by a quarter of the sample and the other subjects are not so far off. The latter is met by an even larger proportion of our sample (more than 50\%). However, the intake of fruit and vegetables of subjects in the lowest intake group was half that of subjects in the highest intake group. Convincing this part of the population to come back to the Mediterranean tradition by eating more fruit and vegetables might be a priority for nutrition education in Italy.

\section{Acknowledgement}

This study was financed by the Italian Ministry of Agriculture (Mi.R.A.A.F., presently Mi.P.A.).

\section{References}

Carnovale E \& Marletta L (1997) Tabelle di composizione degli alimenti. Rome: Istituto Nazionale della Nutrizione.

Cialfa E, Turrini A \& Lintas C (1991) A National Food Survey. Food Balance Sheets and other methodologies. A critical overview. In Monitoring Dietary Intakes pp. 23-44 [I Macdonald, editor] Berlin: Springer-Verlag.

Conforti P, D'Amicis A, Turrini A \& Cialfa E (1996) I consumi alimentari in Italia. Quadro attuale e tendenze recenti. Atti della Seconda Consensus Conference Italiana 1986-96. Abbassare la colesterolemia per ridurre la cardiopatia coronarica, Rome.

FAO (1992) Agrostat/PC. Rome: FAO.

Ferro-Luzzi A \& Branca F (1991) Mediterranean diet, Italian-style: prototype of a healthy diet. American Journal of Clinical Nutrition 61, 1338S-1345S.

Ferro-Luzzi A \& Leclercq C (1997) Nutrition policy in Italy: state of the art. In Implementing Dietary Guidelines for Healthy Eating, pp. 159-174 [V Wheelock, editor]. London: Chapman \& Hall.

Ferro-Luzzi A \& Sette S (1989) The Mediterranean diet: an attempt to define its present and past composition. European Journal of Clinical Nutrition 43, 12S2-29S2.

Ferro-Luzzi A, Cialfa E, Leclercq C \& Toti E (1994) The Mediterranean diet revisited. Focus on fruit and vegetables. International Journal of Food Sciences and Nutrition 45, 291-300.

ICN (International Conference on Nutrition) (1992) Italian Country Paper for the International Conference on Nutrition. Rome: National Institute of Nutrition.

ISTAT (1995) Popolazione e abitazioni, $13^{\circ}$ Censimento Generale della Popolazione e delle Abitazioni 20 ottobre 1991. Rome: Fascicolo nazionale ITALIA.

Keys A (1995) Mediterranean diet and public health: personal reflections. American Journal of Clinical Nutrition 61, 1321S$1323 \mathrm{~S}$.

NIN (1986) Linee guida per una sana alimentazione italiana. Rome: Istituto Nazionale della Nutrizione e Ministero dell'Agricoltura e Foreste.

NIN (1997) Linee guida per una sana alimentazione italiana. Rome: Istituto Nazionale della Nutrizione.

Pilo V (1991) Gearing the Mediterranean agro-alimentary sector to a health-promoting dietary model. In Food and Nutrition Policy in Mediterranean Europe. Proceedings of a WHO Symposium. WHO C.C. Nutrition Series 1, 205-210 [A Ferro-Luzzi, E Cialfa and C Leclercq, editors]. Rome: National Institute of Nutrition.

Saba A, Turrini A, Mistura G, Cialfa E, Vichi M (1990) Indagine nazionale sui consumi alimentari delle famiglie 1980-84: alcuni principali risultati. Rivista della Società Italiana di Scienza dell'Alimentazione 19, 53-65.

Saccomandi V (1991) Linking agricultural policy with policy for food and nutrition. In Food and Nutrition Policy in 
Mediterranean Europe. Proceedings of a WHO Symposium. WHO C.C. Nutrition Series 1, 201-204. [A Ferro-Luzzi, E Cialfa and C Leclercq, editors]. Rome: National Institute of Nutrition.

SINU (Italian Society for Human Nutrition) (1996) Livelli di Assunzione giornalieri Raccomandati di energia e Nutrienti per la popolazione italiana (Revisione 1996). Rome: Italian Society for Human Nutrition.

Ticca M (1991) Food and nutrition policy: the Italian experience. In Food and Nutrition Policy in Mediterranean Europe. Proceedings of a WHO Symposium. WHO C.C. Nutrition Series 1, 153-160. [A Ferro-Luzzi, E Cialfa and C Leclercq, editors]. Rome: National Institute of Nutrition.

Turrini A, Saba A \& Lintas C (1991) Study of the Italian reference diet for monitoring food constituents and contaminants. Nutrition Research 11, 861-974.

WHO (1990) Diet, nutrition, and the prevention of chronic diseases. Report of a WHO Study Group. Technical Report Series 797. Geneva: WHO. 